results are in agreement with recent studies that report higher borderline intellectual functioning and lower IQ scores in school-aged LPT.

Parental assessment on LPT showed increasing visual and hearing impairment until school-age, difficulties in language/ speech until 5y.o., a high rate of grade retention, increased signs of childhood behavior problems, but not higher rates of ADHD. LPT's parents should be informed about the possible late complications. Special attention and follow-up must be paid to LPT from the beginning for timely detection and intervention in capacities that can impair neurodevelopment, hearing-speech-language and learning capability of these children.

\section{CLINICAL AND PREVENTIVE EFFICACY OF PHYTOPREPARATIONS IN PRE-SCHOOL CHILDREN WITH ADENOTONSILLAR PATHOLOGY}

Vera Vavilova*, Alexsander Vavilov, Asya Cherkaeva, Irina Nechaeva, Vitalyi Tiuliukin. Kemerovo State Medical University

\subsection{6/archdischild-2021-europaediatrics.471}

Assessing efficacy of Tonsilgon $\mathrm{N}$ in pre-school children as an etiotropic drug in complex therapy of adenotonsillar pathology at the rehabilitation stage.

Within the period from 2011 to 2015, 1,076 children (aged from 2 to 5 years) with a history of pathology of nasopharyngeal and palatine tonsils in $100 \%$ of cases were reviewed. Pre-school children were given Tonsilgon $\mathrm{N}$ phytopreparation in the form of drops in age-specific doses within 30 days.

The control group included 200 children. The phytopreparation efficacy was analyzed before and after the preventive therapy.

A year prior to the preventive therapy, degree II nasopharyngeal tonsil hypertrophy complicated by adenoiditis was noted in $71.3 \%$ of children in the treatment group and in $74.5 \%$ of children in the control group. Degree III nasopharyngeal tonsil hypertrophy made $28.7 \%$ and $25.5 \%$, respectively. A year after the rehabilitation therapy, only $32.9 \%$ of patients in the treatment group did not show improvement in the clinical presentation. Symptoms of adenoiditis were practically relieved in half of the patients, nasal breathing was restored in $95.8 \%$ of patients, the size of a nasopharyngeal tonsil was reduced from degree II to degree I in $64.9 \%$ of patients.

Normalization of the rhinoscopy presentation was noted in $82 \%$ of patients, $77.9 \%$ of patients showed reduction of the ARI rate from 5-8 to 2-3 times a year. Endoscopic control confirmed reduction of size of both nasopharyngeal and palatine tonsils in $64.9 \%$ of patients. The hypertrophy degree of nasopharyngeal and palatine tonsils in pre-school children not receiving Tonsilgon $\mathrm{N}$ phytopreparation did not show any change. In addition, hypertrophy demonstrated increase from $74.5 \%$ to $83 \%$ over time.

Prospective study of children receiving Tonsilgon $\mathrm{N}$ as a rehabilitation method demonstrated its efficacy on immune development of the respiratory tract. The obtained data allow us to recommend Tonsilgon $\mathrm{N}$ to be included in programs of immune rehabilitation and prevention of exacerbation of adenotonsillar pathology.

\section{2 EUROPEAN ONLINE SEARCH PATTERNS OF FLU VACCINATION DURING THE COVID-19 PANDEMIC}

Inês Silva Costa*, Madalena Meira Nisa, Lígia M Ferreira. Pediatrics Department, Centro Hospitalar Tondela-Viseu EPE, Portugal

10.1136/archdischild-2021-europaediatrics.472

Google Trends (GT) is an online data tool that measures Relative Search Volume (RSV). In medical settings, it has proven to be associated with patient's perceptions and even changes in search for medical care. To identify a possible increase in online search patterns about flu vaccination during the COVID-19 pandemic, we conducted a GT analysis in a group of European countries.

A GT analysis with the GT topic 'flu vaccine' was performed between 2016 and 2020. Retrieved RSV was represented between 0 and 100 (highest interest in the query). Two groups of countries were selected, according to the reported incidence rate of COVID-19 by the European Center for Disease Prevention and Control, between week 37 and 41 of 2020, in children under 15 years (highest incidence: Belgium, Czech Republic, Spain, Portugal and Denmark; lowest incidence: Poland, Sweden, Norway, Finland and Greece).

Flu vaccination season (FVS) is considered to be, yearly, between week 38 and 44 and COVID-19 pandemic (CVP) from week 4 of 2020, as the first reported case in Europe was diagnosed.

Median RSV about 'flu vaccine', before the COVID-19 pandemic, varied between 0 (Czech Republic and Portugal) and 4 (Belgium and Poland) outside the FVS and between 0 (Czech Republic) and 31 (Greece) during the FVS.

As the CVP settled, the online search increased significantly, outside the FVS in every country $(\mathrm{p}<0.05)$, except in Czech Republic $(p=0.216)$. During the FVS, the search patterns also increased in every studied country $(p<0.05)$, but not in Finland $(\mathrm{p}=0.214)$.

As to the percentage of increase in RVS (during the FVS), before and during the CVP, the top 5 countries were, in order: Czech Republic (>5200\%), Spain (484,6\%), Poland (400,0\%), Denmark (311,8\%) and Portugal (280\%). Belgium placed ninth in increase rate, with $149,0 \%$.

Flu vaccination is one of the most acknowledged public health measures, and its online search interest usually peaks as the FVS begins every year.

During the FVS in 2020, 4 out of the 5 countries with the highest incidence of COVID-19 in children $<15$ years ranked in the top 5 studied countries with the highest increase in online search of flu vaccine.

\section{VALIDITY OF THE AGES AND STAGES QUESTIONNAIRE FOR DETECTING LATER BELOW AVERAGE COGNITIVE FUNCTION}

${ }^{1}$ Andrea Bowe*, ${ }^{2}$ Jonathan Hourihane, ${ }^{3}$ Anthony Staines, ${ }^{4}$ Deirdre Murray. ${ }^{1}$ INFANT Research Centre, Paediatric Academic Unit, Cork University Hospital, Wilton, Cork, Ireland; ${ }^{2}$ INFANT Research Centre, Cork, Ireland; Paediatrics, Royal College of Surgeons in Ireland, Dublin, Ireland; ${ }^{3}$ School of Nursing, Psychotherapy and Community Health, Dublin City University, Dublin, Ireland; " INFANT Research Centre, Cork, Ireland; Department of Paediatrics and Child Health, Cork University Maternity Hospital, Wilton, Cork, Ireland

10.1136/archdischild-2021-europaediatrics.473 